\title{
The Environmental Impact of Organizations: A Pilot Test from the Packaging Industry Based on Organizational Life Cycle Assessment
}

\author{
Michela Rimano ${ }^{1}$, Alberto Simboli ${ }^{2}\left(\mathbb{D}\right.$, Raffaella Taddeo ${ }^{2, *(\mathbb{D}}$, Michele Del Grosso ${ }^{1,2}$ and Andrea Raggi $^{2}$ \\ 1 Aptar Italia S.p.A., Via Po 49, San Giovanni Teatino, 66020 Chieti, Italy; michela.rimano@aptar.com (M.R.); \\ michele.delgrosso@aptar.com (M.D.G.) \\ 2 Department of Economic Studies, University “G. d'Annunzio", Viale Pindaro 42, 65127 Pescara, Italy; \\ a.simboli@unich.it (A.S.); a.raggi@unich.it (A.R.) \\ * Correspondence: r.taddeo@unich.it
}

check for updates

Citation: Rimano, M.; Simboli, A.; Taddeo, R.; Del Grosso, M.; Raggi, A. The Environmental Impact of Organizations: A Pilot Test from the Packaging Industry Based on Organizational Life Cycle Assessment. Sustainability 2021, 13 , 11402. https://doi.org/10.3390/ su132011402

Academic Editor: John Carman

Received: 23 August 2021 Accepted: 12 October 2021 Published: 15 October 2021 Corrected: 31 January 2023

Publisher's Note: MDPI stays neutral with regard to jurisdictional claims in published maps and institutional affiliations.

Copyright: (c) 2021 by the authors. Licensee MDPI, Basel, Switzerland. This article is an open access article distributed under the terms and conditions of the Creative Commons Attribution (CC BY) license (https:/ / creativecommons.org/licenses/by/ $4.0 /)$.

\begin{abstract}
This article presents and discusses a pilot test concerning the environmental impacts assessment of organizations. The study was conducted in a production site of a world leading group in the plastic packaging industry. The purpose was to deepen the knowledge of the methodologies currently available and also of the benefits and the difficulties related to their practical implementation. The analysis was conducted in the period 2018-2019, in line with ISO 14044 and ISO/TS 14072 standards and therefore inspired by the organizational life cycle assessment (O-LCA) procedures and standards. The O-LCA test application has proved useful in detecting a number of environmental hotspots usually not detected by other life cycle based approaches, on which the organization should focus to undertake improvement actions, both internal and external (e.g., the category "employees commuting"). The experience gained in the production site under study also led to the replication of the assessment approach to other facilities around the world and for informing corporate sustainability reporting activities (e.g., Global Reporting Initiative and Carbon Disclosure Project reporting standards). Such results can provide methodological and practical insights to both scholars and practitioners in that field of activities.
\end{abstract}

Keywords: organizational life cycle assessment; O-LCA; ISO/TS 14072; corporate sustainability; environmental impact assessment; plastic packaging industry

\section{Introduction}

Corporate sustainability implies the adoption of technological, organizational, and managerial solutions aimed at increasing the environmental and economic and social performances of companies at various levels [1-3]. At present, the most common methodologies in use mainly refer to product and process systems and are based on life cycle-based approaches [4]. Methodologies dedicated to entire organizations can expand the possibilities of representing all aspects and activities related to their operation, thus improving the potential capabilities of evaluating and communicating the performance gained and developing more sustainable strategies and actions accordingly. Such methodologies are capable of analyzing entire organizations (organizational approach), also including upstream and downstream activities besides the internal facilities (life cycle approach); they consider a number of relevant environmental aspects (multi-impact approach) and provide organizations with additional environmental understanding, effectively supporting them in improving their performance $[5,6]$.

The most promising methodologies detected are the Organization Environmental Footprint (OEF) [7] and the Organizational Life Cycle Assessment (O-LCA) [8]. The former was developed by the European Commission and is the subject of the Recommendation of the European Union on the Use of Common Methods to Measure and Communicate 
the Life Cycle Environmental Performance of Products and Organizations [7]. The latter was issued by the ISO/TS 14072 technical standard [8] and is the subject of the Guidance on Organizational Life Cycle Assessment developed by UNEP and SETAC [9]. Despite over fifteen years having elapsed since the first attempts of life cycle-based environmental analysis of organizations started to emerge, applications of OEF or O-LCA are not yet a common practice.

Considering the characteristics and the requirements of the above-mentioned methodologies, it was decided to carry out this study following the O-LCA methodology, mainly for two reasons: (i) O-LCA is regulated by an international standard (this is particularly relevant since the organization under investigation is part of a multinational corporation operating worldwide); (ii) O-LCA is more flexible in terms of setting the analysis [5].

With the aim of highlighting the potential (and the limitations) of that methodology, this article presents and discusses the test implementation of O-LCA in a production site (consisting of two facilities located in the same area) of a world leading group in the plastic packaging industry for beauty and home, pharmaceuticals, and food and beverage products. This sector has recently been strongly concerned with identifying and reducing the environmental impacts of its productions [10,11]; for this reason, the case studied proves to be particularly significant for its effort to extend this purpose also to the entire organization.

After a short background about the methodology, the main steps of the implementation of the O-LCA in the organization selected are described, highlighting the synergies and the critical issues that emerged; as this was a pilot test with even methodological purposes, these aspects are deepened in reference to each step of the study. At the end, the results obtained are critically discussed, and conclusions are drawn.

\section{General Rules for the Environmental Impact Assessment of Organizations}

As recalled and suggested by the ISO/TS 14072 standard [8], the study was structured in the following phases: goal and scope definition, life cycle inventory analysis, life cycle impact assessment, interpretation of results. During the first phase of the analysis, the objective of the study, the system boundaries, the functional unit to which the results are to be reported, and the categories of environmental impact considered were defined. The life cycle inventory included all activities aimed at collecting and processing data relating to all inputs and outputs (both in terms of mass and energy) of the organization considered. In the impact assessment, inputs and outputs identified in the previous phase were converted into potential environmental impacts by applying the related characterization factors to the inventory data. In this way, a profile of the organization's potential environmental impacts was obtained, consisting of the results of the various impact categories considered. The phase of interpretation of the results allowed us to derive conclusions and recommendations on which, for example, to base a communication strategy and a process of replication of the test in other plants of the group.

Particular attention must be paid to the first phase since, compared to what is required for a product LCA, it is the one that most presents peculiarities when referring to an organization [12]. As for the conventional LCA procedure [13,14], the goal of the study must be clearly specified because it is decisive for all the subsequent O-LCA phases [9]; the scope should be unique and sufficiently well-defined to ensure that breadth, depth, and detail of the study are compatible and sufficient to address the stated goals [13]. However, some features of the O-LCA differ from a conventional LCA procedure; they are specified hereafter according to the Guidance on Organizational Life Cycle Assessment [9]:

(i) It is necessary to disaggregate the unit of analysis, i.e., the reporting unit, into two elements, which correspond to description (Reporting Organization (RO)) and quantification (reporting flow). The organization shall consolidate all its units or parts (e.g., business divisions, brands, facilities) following the control approach (operational or financial) or the equity share approach. 
(ii) The reporting period (i.e., the specific time period for which the organization is being studied) needs to be established, as the results are valid for that period. It is recommended that it be one operation cycle of the organization (in accordance with financial and other reporting schemes; one year is the preferred option).

(iii) The system boundary shall be defined to include direct as well as indirect resource use and emissions; the former occur within the reporting organization, while the latter take place throughout the value chain related to the organization's activities. Moreover, supporting activities should be included (e.g., marketing, stock storage, research and development, heating in offices).

(iv) The inventory analysis is the phase where an analogical model of reality is built to faithfully represent the exchanges between each operation that takes place during the life cycle of the organization. It is the phase that requires the most time and resources since it is the phase in which all inputs and outputs of the activities included in the system boundaries must be identified and quantified, both inside and outside the company gates.

(v) A complete cradle-to-grave assessment should include the resource consumption and emissions of the use and the end-of-life phases (i.e., waste disposal and treatment) of the products sold in the reporting period. However, if an organization has no influence on the use and the end-of life stage of its products (e.g., via product design or recycling campaigns), a cradle-to-gate perspective may be adopted (i.e., up to the gate of the reporting organization), thus excluding the downstream stages. The latter situation is quite common for raw materials and intermediate products [9].

\section{The Pilot Test Conducted: Methodological and Practical Features}

This section presents and discusses the methodological settings and the practical results related to the four phases of the O-LCA applied to the study conducted. Our intention was to test the methodology to understand its benefits, limits, and criticalities and evaluate its potential fallout within the organization.

The study was conducted in the period 2018-2019 according to ISO [12,13] and ISO/TS 14072 [8] standards and was mainly based on primary data and internal documentation provided by the organization (referring to the financial year 2017). The organization selected as a case study operates in the business unit of personal care and home care products and together with other business units (fragrance, skincare, and color cosmetics) constitutes the division "Beauty\&Home" of the group. The organization manufactures and assembles plastic-made dispensers and micro-pumps, which are meant to be part of finished products such as perfumes, soaps, and lotions. This RO was selected to pioneer the application of O-LCA because it is a representative unit of operation with previous experience with environmental impact management and assessment issues.

\subsection{Goal and Scope Definition}

The main goals that the company decided to pursue carrying out the O-LCA study were (i) gaining insight into internal operation and the whole value chain and ii) identifying environmental hotspots at different unit levels.

The intended application was to develop a model that, starting from the results of the pilot test conducted in the production site selected, would be extended to other sites and divisions of the organization and could be exploited for reporting and communication initiatives.

The RO is composed of two facilities (plant A and plant B), which are so closely connected from organizational, managerial, and productive points of view that they can be considered as a unique production site.

The reporting flow was the total amount of products, i.e., dispensers and micro-pumps, manufactured during the year considered. 
The reference period was one financial year (2017). This is consistent with the goal and the scope of the study because it is a reasonable period to represent the activities regularly carried out by the organization.

The consolidation method selected was the operational control; therefore, all activities and related life cycle processes of the RO were considered according to ISO/TS 14072. This method led us to include in the system boundaries the units over which the organization or one of its subsidiaries has the full authority to introduce and implement its operating policies and operation. Under this approach, the organization accounts for $100 \%$ of the impacts from units over which it has operational control.

The system boundary was defined following the cradle-to-gate approach. The reasons were mainly as follows:

i. the products manufactured by the organization are not directly sold to the end market; therefore, the RO has no influence on the way they are distributed to final consumers, used, and disposed of;

ii. the use of the dispensing system itself does not generate any impacts on the environment.

Figure 1 shows the activities, both direct and indirect (upstream and downstream), included in the system boundary, as identified by the O-LCA guidelines [9].

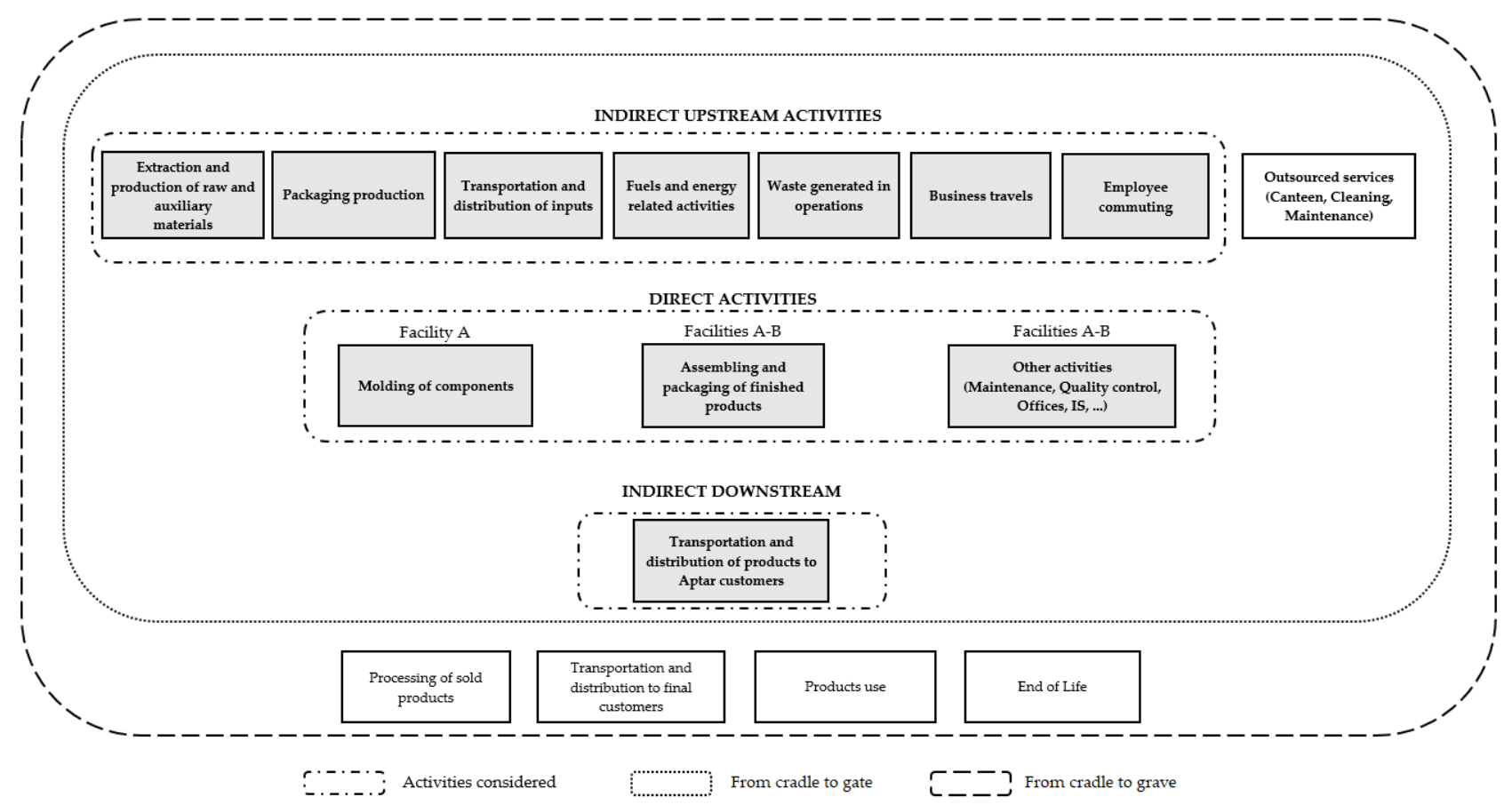

Figure 1. Activities included in the system boundary.

Precisely, the indirect upstream activities considered were:

- extraction and production of raw and auxiliary materials;

- packaging production;

- transportation and distribution of inputs (e.g., raw materials, components, products and packaging from suppliers to $\mathrm{RO}$ );

- fuels and energy related activities;

- waste generated in operations;

- business travels;

- employee commuting. 
The services performed by external organizations (such as the canteen service, the cleaning service, and the maintenance of structural elements) do not fall within the scope of consolidation and therefore were not included in the system boundary.

The direct activities included in the system boundary were:

- $\quad$ molding of components;

- $\quad$ assembling and packaging of finished products;

- other activities (maintenance of machines and equipment, quality control, offices, server power supply, heating, ventilation, and air conditioning-HVAC).

Finally, the indirect downstream activities enclosed were:

- transportation and distribution of RO products to customers (or to other plants of the group).

Among these various indirect activities, only transportation and distribution to tier 1 clients were considered. As aforementioned, activities such as processing of the final product, transportation and distribution of the final product, use of the final product, and its end-of-life treatment/disposal were excluded due to fact that the RO has no influence on them.

\subsection{Life Cycle Inventory Analysis}

In order to carry out an exhaustive inventory of the data and the information required by an O-LCA, multiple data collection forms were used (at least one for each activity), compiled with information and data provided by the different departments and by the various actors in the supply chain.

A top-down approach was followed that considers the reporting organization as a whole and adds upstream and downstream modules for inputs and outputs [9], and the data collected were, in almost all cases, specific data. In particular, the inputs considered were raw and auxiliary materials, components and semi-finished products, energy, water, fuels, packaging, maintenance and offices products, and refrigerants. Furthermore, transportations, business travels, and employee commuting were considered. On the other hand, the observed outputs were semi-finished and finished products, scraps (most of which are reused internally), and solid, liquid, and gaseous emissions. The organization uses certified electricity from hydroelectric sources. No cut-offs were applied.

The following activities were identified according to Figure 1.

- $\quad$ Extraction and production of raw and auxiliary materials: The raw and the auxiliary materials considered in the inventory were all those used to obtain the total production of the reference year. To identify them, it was necessary to analyze the production processes, interview experienced staff, and draw up the list of inputs.

For the resins used in the molding process, an Excel data sheet was created where the following information was entered: type of material, description, supplier name, supplier address, facility involved in the purchase (plant A or plant B), and quantity purchased during the reference period, expressed in tons. The purchasing manager provided the relevant data.

For the auxiliary materials and other products, data were provided by the purchasing department and the enterprise resource planning (ERP) department, and they were taken with reference to the quantity used in A and B plants, expressed in tons or liters.

Products are assembled using, in addition to the components molded directly in plant A, other components purchased from external suppliers. With regard to the latter, in order to trace back the relevant elementary flows, it was necessary to identify all types of components, which materials they are composed of, and the amounts used in the period under examination. Precisely, to calculate the amount of material expressed in the appropriate unit of measurement (tons), it was necessary to multiply, for each type of component, the number of pieces purchased in the reference year by the specific weight (or average weight, as the case may be) recorded on RO's ERP system, further distin- 
guishing by type of material. In addition, it was reported which site purchased and used the components.

For the components made of more than one material, the relevant bill of materials was consulted to obtain the percentage weights of the different materials.

To collect the necessary information, the quality assurance department was asked to identify all the components and the number of parts purchased, and the ERP department and the product specialist were asked to detect the weights of the components. In some cases, the suppliers communicated the total quantity provided, directly expressed in tons.

- Production of tertiary packaging: Regarding the production of the tertiary packaging, it was necessary to understand how the products are packaged and shipped. The Excel data collection form for this activity tracked the type of packaging (boxes, pallets, bags, ribbons, tape, labels, etc.), the type of material, the description, the SAP code, the unit of measurement, the quantity and the site concerned. The quantities were initially expressed in pieces; in order to transform them into tonnes, the number of pieces had to be multiplied by the specific weight of each type of packaging, extracted from SAP. To identify the materials, the technical sheets or suppliers were consulted. The Purchasing Office provided the information.

- Transportation and distribution (inbound): For the transportation of raw materials, components, products, and packaging, the information collected in the Excel data collection form was: the distance between the supplier and the site where the shipment was destined, the date of shipment, the mode of transportation, the type of transportation, and whether it was directed only to RO sites or also to other organizations (and if mixed, in what percentage).

- Transportation of raw materials: Knowing the address of the supplier, through Google Maps, it was possible to calculate the distance in kilometers traveled for each transportation carried out by road. For sea transportation, the unit of measurement was tkm (ton-kilometer), which is obtained by multiplying the distance traveled by the weight carried; it was assumed that the transportation from the point of departure to the port of departure and then from the port of arrival to the point of arrival took place by road, with distance calculated in kilometers by Navionics. The shipping department and the purchasing manager provided the information.

- Transportation of components: For the transportation of the components, it was not possible to obtain data for each shipment; however, the weekly frequency of deliveries made by each supplier was obtained through interviews with the warehouse department staff. The weekly frequency was then transformed into an annual frequency and multiplied by the distance between the supplier and the relevant site to calculate the mileage. In some cases, it was verified that the same supplier, with a single transportation, had delivered components to both plants A and B; in such cases, only one transportation was counted considering, from time to time, the greater distance depending on the location of the supplier. In circumstances where the frequency was not the same for both sites, a proportional calculation was performed. What was said above about sea transportation also applies here. Supplier addresses were taken from SAP by entering the supplier code.

- Transportation of products and packaging: For the transportation of products and packaging, it was possible to verify delivery data and calculate the distance traveled using Google Maps. Transportation of different products performed in the same day and by the same supplier were processed only once. The purchasing office provided the relevant information.

- Activities related to fuels and energy: In this stage, extraction, production, and transportation of fuels consumed by the RO or burned to produce electricity as well as any losses related to transportation and distribution of electricity were considered. 
The losses mentioned above were quantified as a percentage that was calculated on the total energy generated in the reference year. The exact percentage considered was taken from the EPD of Vattenfall's hydropower, which is representative.

With reference to the production of fuels used in direct activities:

- $\quad$ Regarding leased assets, the kilometers traveled in the year of reference were calculated;

- Regarding diesel for emergency equipment, purchase invoices were consulted.

- Waste generated in operation: To collect data on waste, an Excel data collection form was prepared where, for each waste, the following was entered: European Waste Catalogue code, description of waste, type of waste (hazardous/non-hazardous), type of treatment (recycling/chemical-physical treatment/disposal), percentage of destination for each treatment, quantity in tons. The information was already available due to fact that the RO acquired the Landfill Free Certification, thus it constantly monitors wastes.

- $\quad$ Business trips: With reference to business travels, no data collection form was prepared due to the lack of detailed information regarding travels and overnight stays. This is due to the fact that employees often book hotels, rent cars, and buy bus, train, or airplane tickets on their own, and no record remains other than that of purchase invoices. At the group level, however, the RO is one of the sites that makes the most use of two web-based systems that map these trips; therefore, from a report prepared at the corporate level, it was possible to obtain the amount of $\mathrm{CO}_{2}$ emitted in $61 \%$ of business trips made in the year of reference. The remaining 39\% was excluded from the study.

- $\quad$ Employee commuting: The commuting of employees, also applicable to business travels, is an activity that has never been considered in conventional product LCAs. To quantify its impact, the inventory phase first required an anonymous survey of the number of employees, their residence, and the facility where they work. The human resources manager provided this information. Next, through Google Maps, it was possible to calculate the distance traveled daily by each worker. Specifically, the distance between the city of residence and the production site and back (round trip) was calculated. Once the daily mileage of each employee was obtained, this was multiplied by the number of working days in the year of reference. It should be noted that, for those whose residence is more than $100 \mathrm{~km}$ away from the production site, it was assumed that their residence is in a nearby town.

A second phase was then dedicated to the sampling of personnel cars. In fact, to calculate the impacts related to commuting, it was essential to know what types of cars workers use to get to work. To this end, 80 cars parked in the employee parking area were sampled by brand, model, and power supply.

- $\quad$ Services performed by external organizations: The services provided by external organizations are the canteen service, the cleaning service, and the maintenance services of infrastructures and the related elements (for example, the maintenance of doors, windows, and alarms). These were excluded from the system boundaries because the consolidation method adopted was that of operational control, and the RO does not strictly control these activities.

However, a more in-depth reflection on the inputs of these services is needed.

In principle, the maintenance service described above involves the use of negligible, if any, amounts of electricity. Elementary equipment that does not require power or is battery powered are typically used. Rarely is the use of maintenance products required, but these are purchased and used directly by external organizations, and the RO has no control over this aspect.

As far as the canteen service is concerned, the reasoning is not as linear, because it is not enough to exclude the fuels purchased by the RO and used exclusively to supply the kitchen equipment. In fact, for carrying out the activity, water (for washing food and crockery and for cooking meals) and electricity (for lighting and air conditioning) 
are consumed, and these consumptions are combined with those of other activities and included in the bills payable to the RO. To exclude them, therefore, it was necessary to quantify them.

With regard to electricity, exact consumption was known at the canteen of plant $B$ thanks to a dedicated counter. On the contrary, the precise consumption of the canteen of plant A was not known. However, it was possible to estimate it starting from the specific electricity consumption per square meter of the canteen in plant $B$; this was multiplied by the overall area kitchen and the services of the plant A canteen.

With regard to water consumption, the general services manager estimated that this, in total for the canteen service and the cleaning service, represents $10 \%$ of total water bill consumption. The values thus identified were subtracted from total water consumption. The products used for cleaning are purchased and used directly by external organizations and were therefore excluded from the analysis.

- Molding: The molding activity requires electricity and water to be carried out. The quantity of energy consumed by this activity was determined by measuring instruments placed in the electricity panels which monitor the consumption in the various areas. As regards cooling water, this is used inside a closed circuit to cool the molds. When these are disassembled, some losses occur, which must be reintegrated and mapped by a specific European Waste Catalogue (EWC) code. Therefore, the amount of water reintegrated is exactly the amount of water consumed by the process, and this value was considered.

- Assembling and packaging of products: To undertake the assembly activity, the machines need electricity. Likewise, packaging and storage of products are highly automated and require electricity to pack and to power handling and storage systems. As for the molding activity, also in this case, the measuring instruments placed in the electricity panels measured the consumption for the different areas.

- Other activities: The section "Other activities" included the consumption of electricity, water, fuels, and raw materials that were recorded for carrying out office and maintenance activities and for quality control, gardening, HVAC, and server power supply.

Electricity consumption was identified by subtracting the energy measured for molding, assembling, and packaging activities and the one consumed by the canteen service from the total returned by the year of reference's bills.

The consumption of water was taken from the bills of each site. The consumptions generated by the canteen and the cleaning services were divided between the two plants, setting the calculation, respectively, to the number of employees and to the square meters of covered area. In addition, the consumption attributed to the molding phase was subtracted for plant A.

For the raw materials directly referred to the production process, the purchase invoices were taken as reference, distinguishing between the two production plants. The purchasing office provided this information.

At this stage, data on leased cars used by managers and employees were also entered. For the cars used by the employees from one facility to another, it was possible to trace the mileage traveled in the year of reference by multiplying the liters of fuel purchased by the kilometers that each vehicle travels with one liter. For executive cars, instead, the same calculation was performed as was presented to obtain the annual mileage when discussing employee commuting, with the only difference being that no sampling was done to identify cars types; in fact, since the cars were leased, the necessary data were already available.

Finally, as regards refrigerants, the information was taken from the annual ISPRA report [15].

- Transportation and distribution (outbound): The transportation and the distribution of products to the direct customers of the organization in the year of reference took 
place by road, by rail, by sea, and by air. The shipment department provided the information on shipments.

The data collection form was filled in by entering: customer name, shipping date, country of destination, city of destination, postal code, site from which the shipment began, shipping method, incoterm ${ }^{\circledR}$, description of the incoterm, gross weight of the shipment. Thanks to this information, it was possible to calculate:

- for road and rail transportation, the distance of each shipment using Google Maps;

- for sea transportation, the distance traveled by sea via Navionics and the distance traveled by road from the $\mathrm{RO}$ site to the port of departure and from the port of destination to the gate of the customer using Google Maps;

- for air transportation, the distance between the departure and the arrival airports via TripSpace and the distance traveled by road from the RO site to the departure airport and the destination airport to the customer gate using Google Maps.

Transportation directed to the same customer carried out on the same date and with the same mode of transportation represented a single transportation.

The database referred to for the assessment of the environmental impact of the outbound transportation activity required the tkm as a unit of measurement for rail, sea, and air transportation. To obtain it, it was sufficient to multiply the number of kilometers, calculated as described above, for the weight carried.

The quality of the data was evaluated based on a pedigree matrix [16]. The quality indicators that were taken into consideration were reliability, completeness, temporal correlation, geographical correlation, and technological correlation. According to the matrix, a score of 1 to 5 was assigned, where 1 represents the maximum quality. A column indicates whether the data were specific $(S)$ or generic $(G)$. Table 1 presents the results of the quality data assessment.

Table 1. Data quality assessment.

\begin{tabular}{|c|c|c|c|c|c|c|}
\hline Flow & $\begin{array}{l}\text { Specific or } \\
\text { Generic }\end{array}$ & Reliability & Completeness & $\begin{array}{c}\text { Temporal } \\
\text { Correlation }\end{array}$ & $\begin{array}{c}\text { Geographical } \\
\text { Correlation }\end{array}$ & $\begin{array}{c}\text { Technological } \\
\text { Correlation }\end{array}$ \\
\hline \multicolumn{7}{|c|}{ INPUT } \\
\hline \multicolumn{7}{|l|}{ Electrical energy } \\
\hline $\begin{array}{l}\text { Electrical energy } \\
\text { from renewable } \\
\text { sources }\end{array}$ & $\mathrm{S}$ & 1 & 1 & 1 & 1 & 1 \\
\hline $\begin{array}{c}\text { T\&D losses } \\
\text { Water }\end{array}$ & G & $1 *$ & 2 & 1 & 3 & 2 \\
\hline $\begin{array}{l}\text { Water } \\
\text { Mass }\end{array}$ & $\mathrm{S}$ & 1 & 1 & 1 & 1 & 1 \\
\hline Resins (for molding) & $\mathrm{S}$ & 1 & 1 & 1 & 1 & 1 \\
\hline Resins (components) & $S$ & 2 & 1 & 1 & 1 & 1 \\
\hline Metals (components) & $S$ & 2 & 1 & 1 & 1 & 1 \\
\hline Auxiliary materials & $S$ & 1 & 1 & 1 & 1 & 1 \\
\hline Packaging & $\mathrm{S}$ & 1 & 1 & 1 & 1 & 1 \\
\hline $\begin{array}{l}\text { Maintenance } \\
\text { products }\end{array}$ & $S$ & 1 & 5 & 1 & 1 & 1 \\
\hline $\begin{array}{l}\text { Other products } \\
\text { (e.g., for offices) }\end{array}$ & S & 1 & 1 & 1 & 1 & 1 \\
\hline Fuels & S & 2 & 1 & 1 & 1 & 1 \\
\hline $\begin{array}{c}\text { Refrigerants } \\
\text { Transport }\end{array}$ & $\mathrm{S}$ & 1 & 1 & 1 & 1 & 1 \\
\hline Incoming transport & $\mathrm{S}$ & 2 & 1 & 1 & 1 & 1 \\
\hline $\begin{array}{l}\text { Employee } \\
\text { commuting }\end{array}$ & S & 2 & 1 & 1 & 1 & 1 \\
\hline Business travels & $\mathrm{S}$ & 1 & 2 & 1 & 1 & 1 \\
\hline Outbound transport & $\mathrm{S}$ & 2 & 1 & 1 & 1 & 1 \\
\hline \multicolumn{7}{|c|}{ OUTPUT } \\
\hline $\begin{array}{l}\text { Products and } \\
\text { by-products }\end{array}$ & & & & & & \\
\hline Cartridges & $S$ & 1 & 1 & 1 & 1 & 1 \\
\hline Finished products & $S$ & 1 & 1 & 1 & 1 & 1 \\
\hline $\begin{array}{l}\text { By-products } \\
\text { Waste }\end{array}$ & $S$ & 1 & 1 & 1 & 1 & 1 \\
\hline Waste & S & 1 & 1 & 1 & 1 & 1 \\
\hline
\end{tabular}

* Third party certified (ISO14025). 
As is evident from Table 1, the quality of the data was more than satisfactory. In fact, temporal, geographical, and technological correlations always assumed value 1 (except for the data related to the losses of electricity due to distribution) since all the data collected were related to the reporting period, to the sites under examination, and to the technologies used. The reliability and the completeness of the data also showed very positive values. It should be mentioned that, in the future, greater efforts will be needed to fully quantify the products used for maintenance activities; however, for the moment, this is not a great issue because the related emission factors are not yet available in the databases used.

\subsection{Life Cycle Impact Assessment}

As mentioned, the O-LCA is a methodology developed starting from a multi-criteria approach, nevertheless, at the time when the analysis was concluded, the available databases did not yet contain the emission factors for all the impacts of the non-primary activities, and this would not have allowed the whole organization to be mapped.

Therefore, considering that it was a pilot study with a methodological purpose in accordance with one of the pathways provided for by the guidelines on O-LCA and also in agreement with other studies conducted [9], we preferred to select the indicator that allowed us to cover all the activities included in the boundaries of the analyzed system: the impact category "Climate change-GWP100". The effects in terms of "Climate change" were assessed as tons of $\mathrm{CO}_{2} \mathrm{e}$ using the following midpoint LCIA methods: CML 2015; DEFRA 2017. The databases consulted were GaBi Professional Database [17] and DEFRA Database [18]. The LCIA results were obtained by multiplying the quantities of the input and the output identified for each activity in the inventory phase and the related emission factors using an electronic spreadsheet. Below, an illustration of how the impact assessment phase was conducted is reported.

a. Extraction and production of raw and auxiliary materials: To quantify the potential impact of extraction and production of raw and auxiliary materials, emission factors were identified from both the GaBi database [17] and the DEFRA database [18]; those relating to plastics and metals were identified from the former, while those referring to some auxiliary raw materials and to paper used in offices were from the latter. As mentioned before, it was not possible to analyze the impacts of certain auxiliary materials and products used for maintenance.

b. Packaging production: The emission factors used to analyze the environmental impacts related to the production of packaging were taken from the DEFRA database [18] and included:

- $\quad$ virgin raw materials: extraction, primary processing, production, and transporting materials to the point of sale;

- secondary raw materials: sorting, processing, manufacturing, and transporting of materials to the point of sale.

These factors are useful for reporting efficiencies gained through reduced procurement of material or the benefit of procuring items that are the outcome of a previous recycling process.

c. Fuels and energy related activities: In order to calculate both upstream and core emissions related to electricity production and losses related to its transmission, transportation, and distribution (downstream), the emission factors from the EPD of the Vattenfall's hydroelectric plant [19] were used as representatives of the clean(er) energy RO's suppliers. To assess the impact of producing the fuel used to power the leased cars and the emergency equipment, instead, reference was made to the DEFRA database [18], which shows the emission factors that should be used for emissions associated with extracting, refining, and transporting fuels to the organizations asset prior to combustion. In addition, the impact related to the use of fuel was also calculated considering an additional emission factor provided by DEFRA (2017).

d. Transportation (inbound and outbound): To assess the potential impact of inbound transportation of raw materials, components, products, and packaging as well as to assess 
the impact of outbound transportation of finished products, emission factors were taken from the DEFRA database [18]. Precisely, those emission factors came from the sheet dedicated to the "F'reighting goods" (it is specified that these should be used specifically for shipments of goods by land, sea, or air carried out by a third-party organization, as is the case with RO).

e. Employee commuting and trips made with leased vehicles: In order to calculate the impact generated by home-work journeys and travels between the two facilities, the emission factors considered, taken from the DEFRA database [18], were identified based on the type of vehicle used each time. In fact, the database distinguishes the emission factors by market segment and by fuel.

f. Waste generated during the organization's activities: The emission factors to assess the impacts from the emissions related to the waste generated during the organization's activities were taken from the DEFRA database [18]:

- $\quad$ for landfill, the relevant factors included waste collection, transportation, and landfill emissions;

- for recycling, the relevant factors included only waste transportation to the facilities dedicated to these activities. This complies with the greenhouse gases (GHG) protocol guidelines [20].

The results are shown in Figure 2 and are expressed as tons of $\mathrm{CO}_{2} \mathrm{e}$ since, in addition to $\mathrm{CO}_{2}$, the other GHGs covered by the Kyoto Protocol $\left(\mathrm{CH}_{4}, \mathrm{~N}_{2} \mathrm{O}, \mathrm{HFC}, \mathrm{PFC}, \mathrm{SF}_{6}\right)$ were also considered.
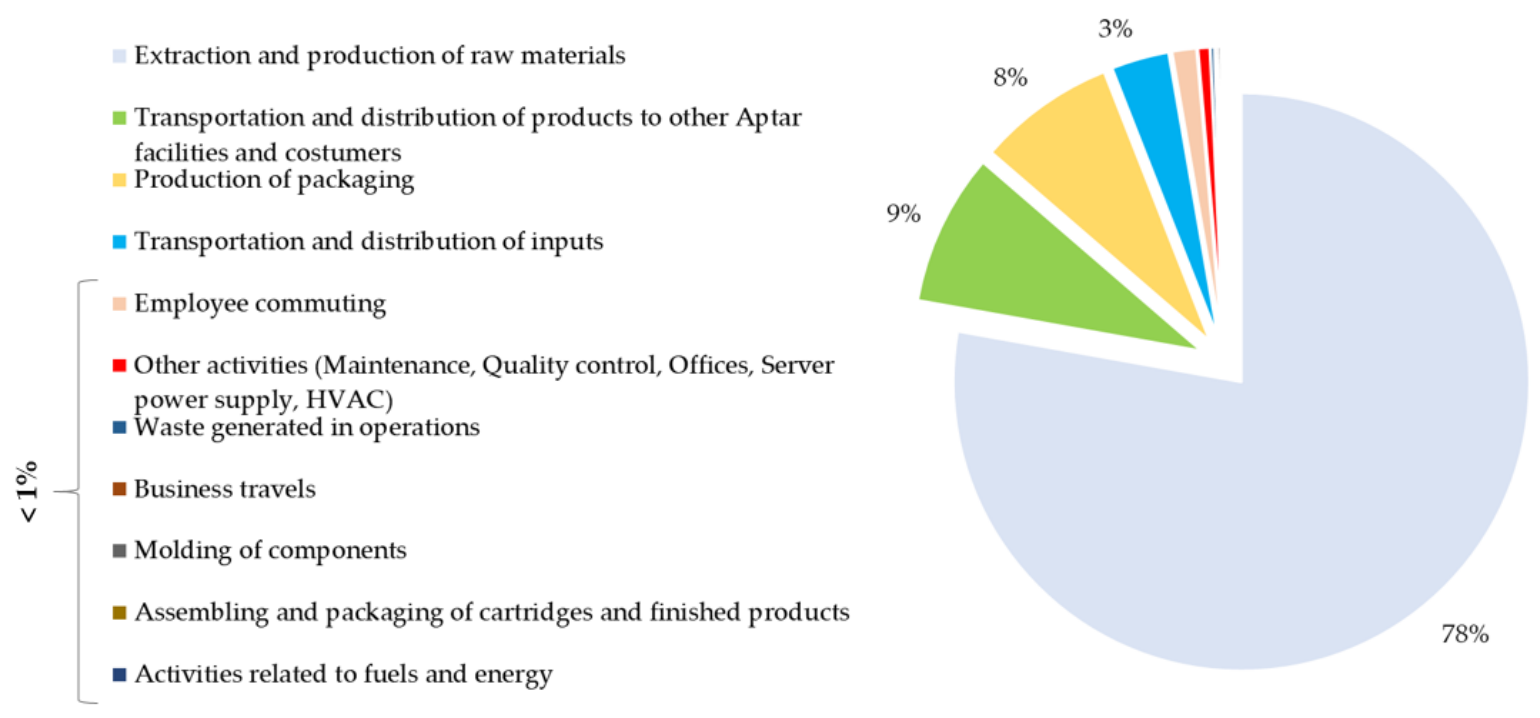

Figure 2. Breakdown of the impact between the activities of the organization.

The potential impact in terms of global warming generated by the organization in the year of reference was found to be 40,755 tons of $\mathrm{CO}_{2} \mathrm{e}$.

To complete the analysis, it was useful to deepen the environmental impact assessment phase by presenting some inventory-level indicators. In particular, the consumption of raw materials (particularly relevant since the phase of their extraction and production proved to be the most impactful one), the consumption of electricity, the consumption of water, and the generation of waste were examined.

Consumption of raw materials: Table 2 shows the quantities of resins and metals that were used to produce the entire product portfolio (reporting flow) during the reference period. The consumption of the various types of plastics reached 8632 tons (PP was the resin most used), while the use of metals was quantified in 2529 tons. These quantities reflect the fact that the dispensers and the micro-pumps are composed mainly or exclusively of resins. 
Table 2. Consumption of raw materials used to produce products components.

\begin{tabular}{cc}
\hline Raw Materials \\
\hline Stainless steel \\
PE \\
Aluminum \\
POM \\
TPC \\
\hline
\end{tabular}

Electricity consumption: In the year of reference, 22,333,977 kWh of electricity were consumed. The molding process of the components absorbed $41 \%$ of total consumption, proving to be the phase of the production process with higher energy intensity, followed by assembling and packaging phases $(28 \%)$, also strongly energy intensive. The entire energy requirement was met by hydroelectricity, as assured by the national energy provider (Table 3).

Table 3. Electricity consumption by activity and facility.

\begin{tabular}{ccc}
\hline Activity & Facility & kWh \\
\hline Molding & A & $9,149,335$ \\
Assembling and packaging & A & $4,692,805$ \\
Assembling and packaging & B & $2,343,866$ \\
Other activities (Maintenance, Quality control, Offices, etc.) & A & $3,931,190$ \\
Other activities (Maintenance, Quality control, Offices, etc.) & B & $2,216,781$ \\
TOTAL & & $\mathbf{2 2 , 3 3 3 , 9 7 7}$ \\
\hline
\end{tabular}

Water consumption: The total consumption of water at the two sites in the year of reference was $13,283 \mathrm{~m}^{3}$. Only a small part can be attributed to the molding process, in which the molds are cooled by water circulating in a closed circuit; here, there is a simple reintegration of the water losses that occur when the molds are changed. Almost all consumption, therefore, is due to water use in the toilets and a small part to maintenance and gardening activities (Table 4).

Table 4. Water consumption by activity and facility.

\begin{tabular}{ccc}
\hline Activity & Facility & $\mathbf{m}^{\mathbf{3}}$ \\
\hline Molding & A & 20 \\
Toilets and showers, maintenance and gardening & A & 6929 \\
Toilets and showers, maintenance and gardening & B & 6334 \\
TOTAL & & $\mathbf{1 3 , 2 8 3}$ \\
\hline
\end{tabular}

Waste generated in operations: Waste was identified and quantified using the EWC (European Waste Catalogue) codes. In plant B, 598 tons of non-hazardous waste and 17 tons of hazardous waste were produced, while plant A generated 847 tons of non-hazardous waste and 16 tons of hazardous waste. It should be noted that the RO holds the "Landfill Free" certification, which guarantees that no more than $10 \%$ of the total waste produced is disposed of in landfills (Table 5).

Table 5. Waste generated in operations by type of waste (hazardous/non-hazardous) and facility.

\begin{tabular}{ccc}
\hline Type of Waste & Facility & Tons \\
\hline Not hazardous & A & 847 \\
Not hazardous & B & 598 \\
Hazardous & A & 16 \\
Hazardous & B & 17 \\
\hline
\end{tabular}




\subsection{Interpretation}

Summarizing the results obtained from the analysis carried out, it is possible to state that:

- The most impactful phase based on the life cycle in regard to the RO turned out to be the phase of extraction and production of raw and auxiliary materials $(78 \%)$. This result is in line with what already emerged from the product LCA carried out on the best-selling product of the company $[19,20]$. It should be noted that the impact would be even more significant if the scraps deriving from the molding process were not internally re-used and reintroduced at that stage.

- The second most impactful phase was the transportation and the distribution of products to customers (9\%). These processes are numerous and located worldwide. Consequently, multiple shipments are made around the world, often using highly impactful means of transportation, such as aircraft and heavy vehicles. Less frequently, shipments are made by sea or rail, which are relatively less impactful.

- The third most impactful phase was the production of packaging, mainly represented by boxes and pallets $(8 \%)$. The former are made almost entirely from recycled paper, and the latter are produced with wood from sustainably managed FSC-certified forests. The greatest impact, however, is to be attributed to the production of packaging made from virgin plastics, which, although used in smaller quantities, results in a less sustainable production process, as shown by the emission factors provided by the database used.

Of the total impact generated by the organization, approximately $99 \%$ is attributable to indirect activities, both upstream and downstream, and less than $1 \%$ derives from direct activities.

The core processes of the $\mathrm{RO}$, such as molding components and assembling semifinished and finished products, require considerable use of electricity; therefore, these activities might be expected to be the most impactful. In fact, this was not the case, since hydropower is purchased instead of grid electricity. To highlight the benefit in terms of avoided $\mathrm{CO}_{2}$ e emissions, two scenarios (grid power mix vs. hydroelectric) were compared considering also the other power-requiring activities of the organization (Table 6).

Based on the actual scenario, the emissions related to the consumption of energy generated from renewable sources amounted to 121 tons of $\mathrm{CO}_{2}$ e for molding, assembling, and packaging activities and to 168 tons of $\mathrm{CO}_{2} \mathrm{e}$ if all the activities carried out by the organization were taken into account. Considering instead a supposed alternative scenario where reference is made to the national energy mix, the impacts were much greater, reaching 5568 tons of $\mathrm{CO}_{2} \mathrm{e}$ for core activities only and 7683 tons of $\mathrm{CO}_{2} \mathrm{e}$ for all activities. This shows that, if RO did not use hydroelectric energy, a considerably greater potential environmental impact would have been generated, attributable in particular to the main production processes.

Having clarified this aspect, another issue remains to be investigated in relation to waste. In fact, it was possible to verify that, during the reporting period, approximately 1478 tons of waste were generated, and 89 tons of $\mathrm{CO}_{2} \mathrm{e}$ were emitted to manage them. Considering the amount of waste produced, a greater impact could be expected from their management. Actually, RO recycles at least $90 \%$ of the waste generated; as already mentioned in the impact assessment phase, for this process, only the impact deriving from the transportation to the recycling plants was considered and not the emissions generated during the recycling process, which are allocated to the relevant recycling organization. 
Table 6. Emissions related to the two electricity supply scenarios (hydropower vs. grid mix).

\begin{tabular}{|c|c|c|c|c|}
\hline $\begin{array}{c}\text { Scenario A-Energy from } \\
\text { Renewable Sources (Hydropower) }\end{array}$ & Facility & kWh & $\begin{array}{l}\text { Emission Factor } \\
\left.\text { (t } \mathrm{CO}_{2} \mathrm{e} / \mathrm{KWh}\right)\end{array}$ & $\mathrm{t} \mathrm{CO}_{2} \mathrm{e}$ \\
\hline Molding & $\mathrm{A}$ & $9,149,335$ & $7.50 \times 10^{-6}$ & 69 \\
\hline Assembling and packaging & $\mathrm{A}$ & $4,692,805$ & $7.50 \times 10^{-6}$ & 35 \\
\hline Assembling and packaging & B & $2,343,866$ & $7.50 \times 10^{-6}$ & 18 \\
\hline \multicolumn{4}{|c|}{ Subtotal core attivities } & 121 \\
\hline $\begin{array}{l}\text { Other activities (Maintenance, Quality } \\
\text { control, Offices, etc.) }\end{array}$ & $\mathrm{A}$ & $3,931,190$ & $7.50 \times 10^{-6}$ & 29 \\
\hline $\begin{array}{l}\text { Other activities (Maintenance, Quality } \\
\text { control, Offices, etc.) }\end{array}$ & B & $2,216,781$ & $7.50 \times 10^{-6}$ & 17 \\
\hline \multicolumn{4}{|c|}{ TOTAL } & 168 \\
\hline Scenario B-Energy from the Grid & Facility & kWh & $\begin{array}{l}\text { Emission Factor } \\
\left.\text { (t } \mathrm{CO}_{2} \mathrm{e} / \mathrm{KWh}\right)\end{array}$ & $\mathrm{t} \mathrm{CO}_{2} \mathrm{e}$ \\
\hline Molding & A & $9,149,335$ & $3.44 \times 10^{-4}$ & 3147 \\
\hline Assembling and packaging & A & $4,692,805$ & $3.44 \times 10^{-4}$ & 1614 \\
\hline Assembling and packaging & B & $2,343,866$ & $3.44 \times 10^{-4}$ & 806 \\
\hline \multicolumn{4}{|c|}{ Subtotal core attivities } & 5568 \\
\hline $\begin{array}{l}\text { Other activities (Maintenance, Quality } \\
\text { control, Offices, etc.) }\end{array}$ & $\mathrm{A}$ & $3,931,190$ & $3.44 \times 10^{-4}$ & 1352 \\
\hline $\begin{array}{l}\text { Other activities (Maintenance, Quality } \\
\text { control, Offices, etc.) }\end{array}$ & B & $2,216,781$ & $3.44 \times 10^{-4}$ & 763 \\
\hline \multicolumn{4}{|c|}{ TOTAL } & 7683 \\
\hline
\end{tabular}

\section{Discussion and Conclusions}

This article presented a pilot test concerning the assessment of the environmental impact of an industrial organization (a production site of a world leader group in the plastic packaging industry). The purpose was to illustrate the methodological choices, the practical steps, and the challenges faced in carrying out the study that was inspired by the organizational life cycle assessment (O-LCA) procedures and standards. Impacts were assessed in terms of GHG emissions. This O-LCA test application provided methodological and practical insights both for scholars and practitioners in this field of activities. In particular, the results obtained from the pilot test conducted allowed the RO the achievement of multiple goals, precisely:

(i) gaining insight into internal operation and value chain by understanding the relationship between activities and processes and the environmental impacts of the product portfolio, thus enabling the design of efficient strategies for their reduction;

(ii) identifying additional environmental hotspots besides those that emerged from the previous product LCA;

(iii) understanding which areas are at risk, e.g., to generate large impacts or to violate any future legal requirements, and identifying impact reduction opportunities in order to support more informed and effective decisions.

These can be considered direct benefits of developing an O-LCA study and would support the systematic use of this assessment practice.

Nonetheless, limitations also emerged:

(i) it was not possible to quantify the amount of some inputs used to perform both preventive and extraordinary maintenance of capital goods (however, their impact, 
compared to the use of mass and energy required by all other activities carried out by the organization, is expected to be negligible);

(ii) the LCIA databases available do not yet contain the emission factors of all non-primary activities, and this resulted in having to limit the study to the "Climate change" category. It is reasonable to expect this limit to be overcome in the near future;

(iii) the data relating to business travels only covered $61 \%$ of the total trips made in the year of reference (however, even if the data on $100 \%$ of the trips were available, the result would not have changed significantly);

(iv) capital goods were not included since it was assumed that plants, machinery, and equipment used have a life extension such that the relevant share of environmental impacts to be allocated to a single reporting period is not significant compared to other sources of impact.

These can be considered aspects to work on to improve the methodology, the attitude of the companies, and the databases useful for carrying out this type of assessment.

Other aspects intended as indirect benefits of the O-LCA pilot test conducted and also as future developments of the study can be considered and include the following.

Based on the knowledge acquired through the analysis, the RO was able to redefine the list of priorities of the impact reduction actions. For the case study conducted, these were as follows: (i) testing alternative materials, such as bio-based or recycled resins, to be used as raw materials, (ii) decreasing the transportation by air, increasing the share of transportation carried out by rail—significantly lowering impact compared to air and road transportation-and (iii) increasing the reuse of packaging materials along the whole supply chain.

In addition, the O-LCA results established a huge information basis for internal and external environmental communication and reporting activities, in particular those completed in compliance with the Global Reporting Initiative (GRI) and the Carbon Disclosure Project (CDP) reporting standards, that benefits from the insightful information provided by the O-LCA test application.

Additionally, considering the usefulness of the data collected in the pilot test, the group worked on the implementation of a new module within the internal software dedicated to environment, health, and safety data management to extend data collection to all sites globally. Currently, all manufacturing facilities (45), corporate offices (4), and warehouse (1) are required to report the following metrics on a monthly basis: use of raw materials, energy consumption, water consumption, waste management, fuels consumption, refrigerants consumption. Thanks to these data, it was possible to calculate the relevant GHG emissions (scopes one, two, and three) for a simplified O-LCA of all the sites and to aggregate the outcomes by region or operating segment. At the end of this process, the company achieved outstanding results, e.g., the ISO 14064 certification for energy and greenhouse gas emission and the prestigious " $\mathrm{A}$ " score on the CDP Climate Change Assessment.

Finally, thanks to the visibility obtained on GHG emissions, the company took part in the Science Based Targets initiative, a collaboration between CDP, United Nations Global Compact, World Resources Institute (WRI), and World Wide Fund for Nature (WWF) with the aim to establish science-based climate targets as standard business practice. By joining this initiative, the group is in alignment with climate science, supporting the transition to a low-carbon economy and formalizing its science-based targets setting emission reduction goals consistent with the requirements to keep global warming well-below $2^{\circ}$ Celsius by 2030 .

As a result of the initial mapping of emissions set up following the O-LCA pilot study, it will be possible to track all the progress made and verify the achievement of targets in the years to come. All these reflections further underline the prospective strategic relevance of the O-LCA methodology.

Author Contributions: Conceptualization, A.S.; Data curation, M.R., R.T. and A.R.; Formal analysis, M.R.; Methodology, A.S., A.R., M.R. and R.T.; Supervision, A.S., M.D.G. and A.R.; Validation, M.D.G.; 
Writing—original draft, M.R.; Writing—review \& editing, R.T. All authors have read and agreed to the published version of the manuscript.

Funding: This research received no external funding.

Institutional Review Board Statement: Not applicable.

Informed Consent Statement: Not applicable.

Data Availability Statement: https:/ /www.gov.uk/government/publications/greenhouse-gasreporting-conversion-factors-2017 (accessed on 10 October 2021).

Conflicts of Interest: The authors declare no conflict of interest.

$\begin{array}{ll}\text { Abbreviations } \\ \text { CDP } & \text { Carbon Disclosure Project } \\ \text { CML } & \text { Center of Environmental Science of Leiden University } \\ \text { DEFRA } & \text { Department for Environment Food \& Rural Affairs (UK) } \\ \text { EPD } & \text { Environmental Product Declarations } \\ \text { ERP } & \text { Enterprise Resource Planning } \\ \text { EWC } & \text { European Waste Catalogue } \\ \text { FSC } & \text { Forest Stewardship Council } \\ \text { GHG } & \text { Greenhouse Gases } \\ \text { GRI } & \text { Global Reporting Initiative } \\ \text { HVAC } & \text { Heating, Ventilation and Air Conditioning } \\ \text { ISPRA } & \text { Istituto Superiore per la Protezione e la Ricerca Ambientale } \\ \text { ISO } & \text { (Higher Institute for Environmental Protection and Research-IT) } \\ \text { LCA } & \text { International Organization for Standardization } \\ \text { LCIA } & \text { Life Cycle Assessment } \\ \text { OEF } & \text { Life Cycle Impact Assessment } \\ \text { O-LCA } & \text { Organization Environmental Footprint } \\ \text { PP } & \text { Organizational Life Cycle Assessment } \\ \text { RO } & \text { Polypropylene } \\ \text { SAP } & \text { Reporting Organization } \\ \text { WRI } & \text { System Application and Product in data processing } \\ \text { WWF } & \text { World Resources Institute } \\ & \text { World Wide Fund for Nature }\end{array}$

\section{References}

1. Wright, G.M.; Caudill, R.J. A more comprehensive and quantitative approach to corporate sustainability. Environ. Impact Assess. Rev. 2020, 83, 1-15. [CrossRef]

2. Yu, C.-C.; Chen, C.-S. From the actual practice of corporate environmental strategy to the creation of a suggested framework of corporate. Environ. Eng. Sci. 2014, 31, 61-70. [CrossRef]

3. White, P. Building a sustainability strategy into the business. Corp. Gov. 2009, 9, 386-394. [CrossRef]

4. Klöpffer, W. Life-Cycle based methods for sustainable product development. Int. J. Life Cycle Assess. 2003, 8, 157-159. [CrossRef]

5. Rimano, M.; Simboli, A.; Taddeo, R.; Raggi, A. Life Cycle Approaches for the Environmental Impact Assessment of Organizations: Defining the State of the Art. Adm. Sci. 2019, 9, 94. [CrossRef]

6. Martínez-Blanco, J.; Atsushi, I.; Finkbeiner, M. Life Cycle Assessment of organizations. In Special Types of Life Cycle Assessment, 1st ed.; Finkbeiner, M., Ed.; Springer: Dordrecht, The Netherlands, 2016; pp. 333-394.

7. European Commission. Recommendation of the Commission of the European Union on the Use of Common Methods to Measure and Communicate the Life Cycle Environmental Performance of Products and Organizations. Annex III: Organisation Environmental Footprint (OEF) Guide. 2013/179/EU. Off. J. Eur. Union 2013, 56, L124.

8. ISO. ISO/TS 14072: Environmental Management_Life Cycle Assessment_Requirements and Guidelines for Organizational Life Cycle Assessment; International Organization for Standardization: Geneva, Switzerland, 2014.

9. UNEP/SETAC. Guidance on Organizational Life Cycle Assessment; UNEP: Paris, France, 2015.

10. Cheung, W.M.; Leong, J.T.; Vichare, P. Incorporating lean thinking and life cycle assessment to reduce environmental impacts of plastic injection moulded products. J. Clean. Prod. 2017, 167, 759-775. [CrossRef]

11. Mannheim, V. Life Cycle Assessment Model of Plastic Products: Comparing Environmental Impacts for Different Scenarios in the Production Stage. Polymers 2021, 13, 777. [CrossRef] 
12. Martínez-Blanco, J.; Atsushi, I.; Finkbeiner, M. Scoping organizational LCA—challenges and solutions. Int. J. Life Cycle Assess. 2015, 20, 829-841. [CrossRef]

13. ISO. ISO 14040: Environmental Management_Life Cycle Assessment_Principles and Framework; International Organization for Standardization: Geneva, Switzerland, 2006.

14. ISO. ISO 14044: Environmental Management_Life Cycle Assessment_Requirements and Guidelines; International Organization for Standardization: Geneva, Switzerland, 2006.

15. ISPRA REPORT. Rapporto Rifiuti Urbani-Edizione 2017. Available online: https://www.isprambiente.gov.it/it/archivio/ eventi/2017/ottobre/rapporto-rifiuti-urbani-edizione-2017 (accessed on 15 March 2018).

16. Weidema, B.P.; Bauer, C.; Hischier, R.; Mutel, C.; Nemecek, T.; Vadenbo, C.O.; Wernet, G. Overview and Methodology: Data quality guideline for the ecoinvent database version 3; Ecoinvent Report; The Ecoinvent Centre: St. Gallen, Swiss, 2013.

17. Thinkstep. GaBi Professional Database. Version 10.0.1.92. 2018. Available online: https://gabi.sphera.com/databases/ professional (accessed on 1 October 2018).

18. DEFRA. Conversion Factors 2017-Full Set (for Advanced Users). 2017. Available online: https://www.gov.uk/government/ publications / greenhouse-gas-reporting-conversion-factors-2017 (accessed on 7 December 2018).

19. Vattenfall AB. EPD of Electricity from Vattenfall's Nordic Hydropower. Registration Number: S-P-00088. UNCPC Code 17, Group 171-Electrical Energy. 2017. Available online: https://gryphon4.environdec.com/system/data/files/6/7470/epd88en\% 20EPD\%202018.pdf (accessed on 14 December 2018).

20. WRI and WBCSD. GHG Protocol Corporate Accounting and Reporting Standard; World Resources Institute: Washington, DC, USA, 2004. 